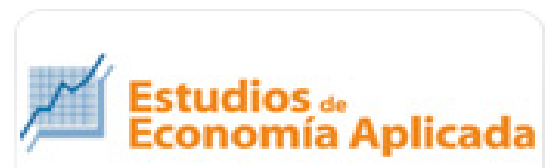
Economia Aplicada

\section{Estudios de Economía Aplicada}

ISSN: 1133-3197

secretaria.tecnica@revista-eea.net

Asociación Internacional de Economía

Aplicada

España

HERNÁNDEZ-VELEROS, ZEUS SALVADOR

Heterogeneous Growth Cycles

Estudios de Economía Aplicada, vol. 28, núm. 3, 2010, pp. 625-650

Asociación Internacional de Economía Aplicada

Valladolid, España

Available in: http://www.redalyc.org/articulo.oa?id=30120334007

How to cite

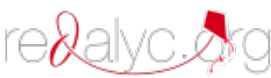

Complete issue

More information about this article

Journal's homepage in redalyc.org

Scientific Information System Network of Scientific Journals from Latin America, the Caribbean, Spain and Portugal Non-profit academic project, developed under the open access initiative 


\begin{tabular}{lllllll}
\hline Estudios de Economía & A plicada & Vol. & $28-3$ & 2010 & PÁgs. & $625-650$ \\
\hline
\end{tabular}

\title{
Heterogeneous Growth Cycles ${ }^{1}$
}

\author{
ZEUS SALVADOR HERNÁNDEZ-VELEROS \\ Instituto de Ciencias Económico-Administrativas \\ UNIVERSIDAD AUTÓNOMA DEL ESTADO DE HIDALGO, MÉXICO \\ e-mail: zshveleros@yahoo.com
}

\begin{abstract}
This paper focuses on the Dirichlet and the Dirichlet-multinomial distributions to analyze one definition of the cycle based on three economic performance regimens: augmentation, stagnation and diminution. We use data from 142 economies grouped in seven clusters during the second half of the last century, a period which has witnessed various structural changes. Furthermore, this paper advances to investigate what the probabilities are of reaching significant positive growth rates - the frequency of the augmentation regimen- which prevailed during the decade from 1950 to 1960 , using Bayesian statistics.

Keywords: Growth Cycles, Long Trend, Dirichlet-Multinomial Distribution, Bayesian Statistics, Structural Change.
\end{abstract}

\section{Ciclos de crecimiento heterogéneo}

\section{RESUMEN}

Este artículo se enfoca en las distribuciones Dirichlet y Dirichlet-multinomial para analizar una definición de ciclo basada en tres regímenes de desempeño económico: incremento, estancamiento y decrecimiento. Empleamos datos del producto interno bruto per cápita 142 economías agrupadas en siete clusters, correspondientes al periodo 1950-2000, el cual ha sido testigo de diferentes cambios estructurales. Asimismo, se investiga cuál es la probabilidad de que se presenten las frecuencias de las tasas de crecimiento positivas significativas - frecuencias del régimen de incremento - observadas en los años cincuenta, gracias al uso de estadística bayesiana.

Palabras clave: Ciclos de crecimiento, tendencia de largo plazo, distribución Dirichet-multinomial, estadística bayesiana, cambio estructural.

Clasificación JEL: E32, O47.

Artículo recibido en enero de 2010 y aceptado en junio de 2010.

Artículo disponible en versión electrónica en la página www.revista-eea.net, ref. อ-28305.

\footnotetext{
${ }^{1}$ Allow me to thank José Antonio García-Durán de Lara, Eduard Berenguer, Jaume Ventura, Josep Luis Carrion i Silvestre, Pablo Mejía Reyes, Ángel Mauricio Reyes Terrón, Juan Francisco Islas Aguirre, Gonzalo Dolores de la Merced, Jordi Melé Carné and two anonymous referees for their valuable comments.
}

ISSN 1697-5731 (online) - ISSN 1133-3197 (print) 


\section{INTRODUCTION}

Easterly et al. (1993) expose that growth rates are highly unstable over time (with a correlation across decades of 0.1 to 0.3 ), in comparison with country characteristics, which are considered decisive for growth, and are very stable or persistent (with cross-decade correlation of 0.6 to 0.9 ). These authors also explain that the low persistence of growth rates reconciles the enormous variation in growth rates across countries with the remarkable stability of relative incomes across countries. In addition, they show that much of the variance in growth rates can be explained by shocks (these indirectly influence growth by changing the variables in economic policy), thus, one should be careful when attributing the high growth rates to good economic policies, they might simply be good luck.

Structural changes at economic time series affect trends, serial correlations, volatilities, and duration of cycle phases. Therefore, if these parameters change we must consider them in our theoretical and empirical analyses.

Hernández-Veleros (2008) establishes a definition of the statistical relation cycle between persistence (duration) and volatility (variability) for three economic performance regimens (augmentation - increase regime-, diminution - decrease regime - and stagnation) of the per capita Gross Domestic Product (PCGDP) of 142 economies grouped in seven clusters for the period from 1950 to 2000 , under the assumption of homogeneity or stability in the vector of probabilities of a multinomial distribution and from this relationship develops a long term growth trend and its respective volatility.

However, if the probabilities of the regimens do not remain constant, then we have structural changes and, therefore, overdispersion in a growth cycle defined by a multinomial distribution. Hence, the most convenient distribution to obtain the variance-covariance matrix for regimens is the Dirichlet-multinomial distribution.

If these structural changes in probabilities happen, then we must ask ourselves what the probabilities are in order to reach the proportions of the significant positive growth rates that prevailed from 1950 to 1960 . We try to answer this question using Bayesian statistics.

Our purpose is to test the following hypotheses:

1. There is a significant overdispersion between economic performance regimens if we employ the multinomial distributions to estimate a growth cycle. Thus, we need to use the Dirichlet-multinomial distribution to study the volatility and correlation between these regimens; and,

2. There is a high probability that all clusters reach the proportions of significant positive growth rates —augmentation regimen— which prevailed during the decade from 1950 to 1960 .

In the second section of this paper we show the theoretical and practical implications from the structural changes of cycles. Next, we will demonstrate some useful statistical tools for this research: Dirichlet and Dirichlet-multinomial 
distributions, tests to distinguish between a multinomial distribution and a Dirichlet-multinomial distribution, and the Frequentist-Bayes debate (Frequentists assign probabilities to random events according to the frequency of their occurrence or to subsets of populations as proportions of the whole; Bayesians assign probabilities to propositions that are uncertain) and how we can use a Bayesian model in order to forecast proportions. In the fourth section, we develop our analyses of the effects of overdispersion on growth cycles and long term growth trends. The summary and conclusions are found in the fifth section.

\section{STRUCTURAL CHANGES}

\subsection{Changes in average duration of expansions and contractions}

Zarnowitz (1991) shows that business expansions for four countries (the U. S., Germany, France and Great Britain) tended to be much longer and contractions much shorter after World War II, even allowing for the largest errors in the early dating of the period (1857-1990). In addition, he mentions that the average duration of expansions would be considerably increased (both absolutely and relatively) to those of contractions, if he distinguishes between slowdowns (phases of a low. i.e., below-trend but still mainly positive, growth) and contractions (phases of an absolute decline in the overall economic activity).

Larraín and Choy (2003) find that open trade and export diversification reduce the duration of recessions; they employ a time series data set for 51 countries during the period of the first quarter of 1980 to the fourth quarter of 2001 .

\subsection{Changes in volatility}

De Long and Summers (1984) state that the decline in variability since World War II cannot be explained by changes in the composition of economic activity or by the avoidance of financial panics. They affirm that significant factors contributing to economic stability include public and private efforts to regulate expenditures and the increase of price controls.

Watson (1992) explains that the post-war stabilization of the U. S. economy is spurious, caused by differences in the way that pre-war and post-war business cycle reference dates are chosen by the National Bureau of Economic Research (NBER). Watson (1994) also finds some changes in the information used by the NBER, because in the past, research was supported for just a few economic time sequences, which show more volatility than the collective activity. Therefore, expansions and contractions have not been changed, other than between world wars.

Christina D. Romer (1992) measures the business cycle of U. S. during the period of 1884-1990 and she observes that three factors alter the conclusions about the business cycle: the estimates of turning points first from de-trended data and 
after from data in levels that include the secular trend, changes in technique to define turning points and the inclusion for the first time of many nominal variables on the business index and after the exclusion of same. So, when she makes the necessary corrections she only observes longer expansions, with no other changes.

Christina D. Romer (1999) shows that the volatility of annual real macroeconomic indicators and the average severity of recessions have declined slightly, but they are less frequent and more uniform. She explains that this situation (the continuity and the changes in the business cycle) can be explained by macroeconomic policy.

In its study about the business cycles for its 13 member countries, the Organization of Economic Cooperation and Development -OECD- (2002) affirms that the amplitude or volatility of the cycle has decreased for the majority of those economies during the 1990's. This is partially due to the nature and size of the shocks that create changes and the changing factors affecting transmission with the increasing role of services in the economy, the reduction in the importance of inventories, and the adoption of macro-economic frameworks focused upon medium-term objectives for stability. On the other hand, the divergence in activity has decreased (divergence can be measured using the standard deviation of output gaps across countries) while the synchronization has not increased.

Gordon's (2005) research on the decline in the volatility of the U. S. business cycle since the mid-1980's concludes that, using a macro model of three equations, the reduced variance of shocks (supply and demand shocks) was the dominant source of reduced volatility in the business cycle.

Ceccheti et al. (2006) investigate whether the volatility of real output growth has declined for 25 countries using quarterly data from the period of 1970-2003. They examine breaks in persistence and in volatility and identify that the volatility of output growth has declined in 16 countries and is unchanged in nine. In that paper Cecchetti et al. (2006) analyze some of the following explanations for the decline in volatility:

1. Improved inventory management policies.

2. Better monetary policies.

3. Financial innovation and improvements in the assignment of risk.

4. Increased international commercial openness.

5. Luck in the form of smaller shocks.

6. Changes in the composition of output, going from more volatile manufacturing and to more stable services.

7. Changes in the methods used to construct the data.

8. Changes in fiscal policy; and

9. A more stable demand.

Arias et al. (2006) explain that 50 percent of the decline in the cyclical volatility of output since 1983 is caused by a reduction in the volatility of productivity 
shocks and no demand shocks. These kinds of shocks can create this state using a Real Business Cycle model.

Justiniano and Primiceri (2006) investigate the decline in volatility during the Period of Great Moderation, and with their model define that investment-specific technology shocks account for most of the sharp decline in volatility.

Rafiq (2006) analyzes decline in volatility in the area of the Euro, and concludes that the principal causes of the moderation are a combination of improved policy and good fortune.

Aguiar and Gopinath (2007) find shocks that tend to promote growth are the primary source of fluctuations in emerging markets, rather than transitory fluctuations around a stable trend. Hence, they find further support for the notion that the "cycle is the trend" for these economies.

\subsection{Breaks in the long term growth trend}

Hansen (2001) explains that stability implies that parameters (mean, variance and trend) for a specific model are constant over time, and a structural break occurs if at least one of these parameters has changed at some date in the sample period. For example, he defines the following dynamic model: $y_{t}=\alpha+\rho y_{t-1}+e_{t}$, with $E\left(e_{t}^{2}\right)=\sigma^{2}$, if the auto-regressive parameter changes then a modification in the serial correlation happens, when the interceptor $\alpha$ changes the average of the series $y_{t}$ results are altered (if $y_{t}$ is a growth rate we have changes in the trend) and, finally, changes in $\sigma^{2}$ imply changes in the volatility.

This literature of the econometrics for structural changes has three branches. Hansen (2001) tells us: tests for a structural break of unknown timing, estimation of the timing for a structural break and tests to distinguish between a non-stationary series and broken time trends.

Economists don't just look for changes in the duration of cycle phases or in volatility. They also have found breaks in economic series like the PCGDP. They want to know the implications for the growth models and for the long term growth trend from this data generation process. For example, Lau (1997) looks for both endogenous and exogenous growth models if the stationary difference or stationary trend is present. In addition, he affirms that permanent changes in economic fundamentals lead to segmented trends in the former models and shift trends in the latter exogenous growth models.

Perron $(1989,1994)$ analyzes the effects that structural breaks cause to tests on unitary roots: these tend to favour the null hypothesis. Thus, our conclusion is that time series with a unit root or time series are non-stationary. Perron and Zhu (2005) analyze the consistency, rate of convergence and limiting distributions of parameters estimates in three models where the trend function exhibits a slope change: a combined broken trend - no level shift—, a local discrete broken trend - the level shift is relatively small — and a global discrete broken trend - the level 
shift is relatively large - at some unknown date and the errors can be either stationary or have a unitary root; in addition, these authors explain that if we include a level shift as a regressor when it is not needed, it can reduce the rate of convergence and induce a bimodal distribution.

Some tests use the stationarity null hypothesis and have the unit root alternative hypothesis. Huang et al. (1997) show that the presence of structural breaks affects the distribution limit of the KPSS univariate, so that they should be taken into consideration when testing the stability of the panel. This is the situation of Carrion-i-Silvestre, del Barrio-Castro and López-Bazo's test (2005), which has as null hypothesis: panel stability with the presence of multiple structural breaks. It incorporates an unknown number of changes that shift the average and the trend of individual time series, where the number and position of structural breaks can differ among individuals. They determine the number of structural breaks using the modified Schwarz information criterion (LWZ) ${ }^{2}$.

Hernández-Veleros (2009) employs this last test in order to study Maddison's data (2003) on the PCGDP of 142 economies clustered in seven groups during the period of 1950-2000 and finds 380 breaks: 44, 76, 111, 81 and 68, per respective decade.

\subsection{From a homogeneous growth cycle to a heterogeneous growth cycle}

Hernández-Veleros (2008) establishes the definition of cycle as the statistical relationship between persistence (duration) and volatility (variability) for three economic performance regimens (augmentation, diminution and stagnation) for the PCGDP of 142 economies grouped in seven clusters for the period of 1950-2000, from Maddison's data (2003) with an assumption of homogeneity or stability in the vector of probabilities in a multinomial distribution. From this relationship he arrives at a long term growth trend and its respective volatility.

However, if the average durations of business expansions and contractions change and if the volatility diminishes during the last decades and there are different breaks, then the probabilities don't remain constant as Hernández-Veleros (2008) assumes. Therefore, we have overdispersion and the most convenient distribution to obtain the variance-covariance matrix for regimens is the Dirichletmultinomial distribution.

If these changes in probabilities happen, we must ask: what probabilities, within the clusters in this study of the proportions of significant positive growth rates that prevailed during the decade from 1951-1960 can be reached. We employ the same data, clusters and the equiprobable growth model that Hernández-Veleros (2008) uses in order to do our research (table 1).

\footnotetext{
${ }^{2}$ I thank Dr. Carrion-i-Silvestre for providing me with these codes.
} 
TABLE 1

Economies by cluster grouped according to their 1950 PCGDP.

\begin{tabular}{|c|c|}
\hline Cluster & Economies \\
\hline 1 & $\begin{array}{l}\text { Equatorial Guinea, Botswana, China, Cape Verde, Lesotho, Burma, } \\
\text { Cambodia, Mongolia, Mauritania, Nepal, Bangladesh, Burkina Faso, Mali, } \\
\text { Rwanda, Guinea Bissau, Malawi, Eritrea and Ethiopia, Comoro Islands, } \\
\text { Togo, Burundi, Guinea, Tanzania, Chad, Zaire. }\end{array}$ \\
\hline 2 & $\begin{array}{l}\text { Taiwan, South Korea, Oman, Thailand, Indonesia, Egypt, Swaziland, } \\
\text { Yemen, Libya, Pakistan, India, Vietnam, Mayotte, S. Helena, West Sahara, } \\
\text { Zimbabwe, São Tomé and Principe, Laos, North Korea, Nigeria, Cameroon, } \\
\text { Kenya, Sudan, Gambia, Uganda, Zambia, Central African Republic, } \\
\text { Afghanistan, Niger, Sierra Leone. }\end{array}$ \\
\hline 3 & $\begin{array}{l}\text { Palestine and Gaza, Tunisia, Dominican Republic, Sri Lanka, Jamaica, } \\
\text { Romania, Algeria, } 20 \text { small Asian Countries, Albania, Philippines, Congo, } \\
\text { Honduras, Senegal, Mozambique, Côte d'Ivoire, Benin, Ghana, Iraq, } \\
\text { Somalia, Liberia, Haiti, Angola, Madagascar. }\end{array}$ \\
\hline 4 & $\begin{array}{l}\text { Japan, Greece, Malaysia, Turkey, Seychelles, Costa Rica, Panama, Brazil, } \\
\text { Bulgaria, Iran, Yugoslavia, Jordan, Ecuador, Paraguay, El Salvador, } \\
\text { Morocco, Bolivia, Nicaragua, Djibouti. }\end{array}$ \\
\hline 5 & $\begin{array}{l}\text { Singapore, Hong Kong, Spain, Puerto Rico, Portugal, Mauritius, South } \\
\text { Arabia, Syria, Mexico, Poland, Hungary, } 24 \text { small Caribbean countries, } \\
\text { Colombia, Bahrain, Reunion, South Africa, Namibia, Peru, Lebanon, } \\
\text { Guatemala, Cuba. }\end{array}$ \\
\hline 6 & $\begin{array}{l}\text { Norway, Ireland, France, Belgium, Finland, Austria, } 13 \text { small Western } \\
\text { Europe, Italy, Germany, Israel, Trinidad and Tobago, Chile, Czechoslovakia, } \\
\text { Argentina, Uruguay, U. S. S. R., Gabon. }\end{array}$ \\
\hline 7 & $\begin{array}{l}\text { U. S., Denmark, Canada, Switzerland, Netherlands, Australia, Sweden, U. K., } \\
\text { New Zealand, Venezuela. }\end{array}$ \\
\hline
\end{tabular}

From: Hernández-Veleros (2008). Equiprobable Growth Model and Growth Cycles: An Approximation to Persistence and Volatility.

\section{STATISTICAL METHODS AND TOOLS FOR CHANGES IN PROBABILITIES}

\subsection{Dirichlet and Dirichlet-multinomial distributions}

In order to cover the hypotheses before listed we expose at this section the statistical aspects about Dirichlet and Dirichlet-multinomial distributions and some tests in order to define between a multinomial distribution or a Dirichletmultinomial distribution, and some overdispersion tests. We show the FrequentistBayes debate (Frequentists assign probabilities to random events according to their frequencies of occurrence or to subsets of populations as proportions of the whole; Bayesians assign probabilities to propositions that are uncertain) and how we can use a Bayesian model in order to forecast proportions. 
In the multinomial distribution the probabilities of ocurrence $\left(p_{1}, p_{2}, \ldots, p_{n}\right)$ of the various events are regarded as constant from trial to trial and $m$ is constant too:

$$
f_{\left(x_{1}, \ldots x_{n}\right)}\left(x_{1}, \ldots, x_{n} ; m, p_{1}, \cdots, p_{n}\right)=p\left[X_{1}=k_{1}, \ldots, X_{n}=k_{n}\right]= \begin{cases}\frac{m !}{k_{1} ! \cdots k_{n} !} p_{1}^{k_{1}} \cdots p_{n}^{k_{n}}, & \text { when } \sum_{i=1}^{n} x_{i}=m \\ 0 & \text { otherwise }\end{cases}
$$

Mosimann (1962) considers the case where $\left(p_{1}, p_{2}, \ldots, p_{n}\right)$ are constant within a set of trials but vary randomly from set to set; these random variables have the distribution given by

$$
b\left(p_{1}, \cdots, p_{n} ; l_{1}, \cdots, l_{n}\right)=\frac{\Gamma\left(\sum_{i=1}^{n} l_{i}\right)}{\prod_{i=1}^{n} \Gamma\left(l_{i}\right)} p_{1}^{l_{1}-1} p_{2}^{l_{2}-1} \cdots p_{n}^{l_{n}-1}=\left[B\left(l_{1}, \sum_{i=2}^{n} l_{i}\right) B\left(l_{2}, \sum_{i=3}^{n} l_{i}\right) \cdots B\left(l_{n-1}, l_{n}\right)\right] \prod_{i=1}^{n} p_{i}^{l_{i}-1}
$$

where all $l$ 's are positive. Mosimann (1962) referres to this distribution as multivariate beta-distribution, other authors named it Dirichlet distribution.

Assuming that in (2) the probabilities vary as in the multivariate betadistribution, then the distributions of $X_{1}, \ldots, X_{n}$ is

$$
\left(\frac{m !}{k_{1} ! \cdots k_{n} !}\right) \frac{\left[\Gamma\left(\sum_{i=1}^{n} l_{i}\right)\right]\left[\prod_{i=1}^{n} \Gamma\left(x_{i}+l_{i}\right)\right]}{\left[\prod_{i=1}^{n} \Gamma\left(l_{i}\right)\right]\left[\Gamma\left(m+\sum_{i=1}^{n} l_{i}\right)\right]}
$$

This is the compound multinomial distribution or Dirichlet-multinomial distribution. Thus, assuming the last expression give us the probability of exactly $k_{1}$ occurrences of event one, $k_{2}$ occurrences of event two, etc, in $m$ trials.

We have the following moments of the Dirichlet-multinomial distribution:

$$
\begin{gathered}
E\left(X_{i}\right)=\frac{m l_{i}}{\sum_{i=1}^{n} l_{i}} \\
\operatorname{Var}\left(X_{i}\right)=m\left[\frac{l_{i}}{\sum_{i=1}^{n} l_{i}}\right]\left[1-\frac{l_{i}}{\sum_{i=1}^{n} l_{i}}\right]\left[\frac{m+\sum_{i=1}^{n} l_{i}}{1+\sum_{i=1}^{n} l_{i}}\right]
\end{gathered}
$$




$$
\operatorname{Cov}\left(X_{i}, X_{j}\right)=-m\left[\frac{l_{i}}{\sum_{i=1}^{n} l_{i}}\right]\left[\frac{l_{j}}{\sum_{i=1}^{n} l_{i}}\right]\left[\frac{m+\sum_{i=1}^{n} l_{i}}{1+\sum_{i=1}^{n} l_{i}}\right]
$$

Therefore, the covariance matrix of the Dirichlet-multinomial distribution is

$$
\Lambda_{D M}=\left[\frac{m+\sum_{i=1}^{n} l_{i}}{1+\sum_{i=1}^{n} l_{i}}\right] \Lambda_{M}=\left[\frac{m+c}{1+c}\right] \Lambda_{M},
$$

where $\Lambda_{M}$ is the covariance matrix of the multinomial distribution.

Mosimann (1962) defines that the correlation between any two Dirichletmultinomial variates, $X_{i} \mathrm{y} X_{j}$, whatever the compounding distribution is found to be

$$
\rho_{X_{i} X_{j}}=\frac{\frac{-E\left(P_{i}\right) E\left(P_{j}\right)}{m-1}+\operatorname{Cov}\left(P_{i}, P_{j}\right)}{\left\{\left[\frac{E\left(P_{i}\right)\left[1-E\left(P_{i}\right)\right]}{m-1}+\operatorname{Var}\left(P_{i}\right)\right]\left[\frac{E\left(P_{j}\right)\left[1-E\left(P_{j}\right)\right]}{m-1}+\operatorname{Var}\left(P_{j}\right)\right]\right\}^{1 / 2}}
$$

Thus, the limit of (8) as $m \rightarrow \infty$ is

$$
\frac{\operatorname{Cov}\left(P_{i}, P_{j}\right)}{\left[\operatorname{Var}\left(P_{i}\right) \operatorname{Var}\left(P_{j}\right)\right]^{1 / 2}}
$$

and

$$
\lim _{m \rightarrow \infty} \rho_{X_{i} X_{j}}=\rho_{P_{i} P_{j}}
$$

Correlations due to the constraint are estimated by the formula

$$
r_{i j}=-\sqrt{\frac{\bar{x}_{i} \bar{x}_{j}}{\left(s_{i}-\bar{x}_{i}\right)\left(s_{i}-\bar{x}_{j}\right)}}
$$

where $s_{i}$ is the number of observations in that cluster.

Paul et al. (2005) suggest to calculate the standard errors of the estimates using the exact Fisher information matrix and no based on the asymptotic Fisher information matrix; therefore they show that exact calculation is based on the betabinomial probability function rather than that of the Dirichlet-multinomial. Neerchal and Morel (2005) propose the same procedure. 
Paul et al. (2005) estimate an overdispersion parameter or the intracluster correlation coefficient $\phi$; Neerchal and Morel (2005) estimate other overdispersion parameter $\rho=\varphi^{1 / 2}$; Guimarães (2005) defines the intraclass correlation coeficient and he denotes it as $\rho$, but he estimates the overdispersion parameter $\rho$ of Neerchal and Morel (2005).

We follow Paul et al. (2005) and Neerchal and Morel (2005), so we have that $\varphi=\rho^{2}=1 /\left(1+\sum_{i=1}^{n} l_{i}\right)=1 /(1+c)$. Neerchal and Morel (2005) express the covariance matrix of Mosimann (1962) as:

$$
\Lambda_{D M}=\left[\frac{m+\sum_{i=1}^{n} l_{i}}{1+\sum_{i=1}^{n} l_{i}}\right] \Lambda_{M}=\left[1+\left(\rho^{2}(m-1)\right] \Lambda_{M} .\right.
$$

Guimarães (2005) says that the introduction of covariates that change across groups implies that the intraclass correlation coefficient is not constant across groups.

\subsection{Testing for homogeneity}

In order to test the multinomial distribution against the Dirichlet-multinomial distribution we can employ the distribution of the asymptotic likelihood ratio $(L R)$ and the $C(\theta)$ goodness-of-fit statistic; Paul et al. (1989) recommend the $C(\theta)$ test based on empirical significance level, power and computational simplicity.

Paul et al. (1989) consider in the asymptotic likelihood ratio $(L R) \mathrm{m}$ independent Dirichlet-multinomial samples. Let the $i$ th of the K samples be of size $s_{i}$ and let there be $X_{i 1}, X_{i 2}, \ldots, X_{i n}$ individuals observed in the $n$ classes with parameters $\pi_{1} / \theta, \pi_{2} / \theta, \ldots, \pi_{n} / \theta$, respectively $\left(\sum_{j=1}^{n} X_{i j}=s_{i}, \sum_{j=1}^{n} \pi_{j}=1\right)$. The joint distribution of $X_{i 1}, X_{i 2}, \ldots, X_{i n}$ can be written as

$$
\frac{s_{i} !}{\prod_{j=1}^{n} X_{i j} !} \frac{\Gamma\left(\theta^{-1}\right) \prod_{j=1}^{n} \Gamma\left(X_{i j}+\pi_{j} \theta^{-1}\right)}{\prod_{j=1}^{n} \Gamma\left(\pi_{j} \theta^{-1}\right) \Gamma\left(s_{i}+\theta^{-1}\right)}
$$

Paul et al. (1989) gets the $C(\theta)$ test in order to study homogeneity, he consideriders the log-likelihood $l$ and let

$$
S\left(\pi_{1}, \ldots, \pi_{n}\right)=\left.\frac{\partial l}{\partial \theta}\right|_{\theta=0}
$$


and

$$
\sigma_{\theta j}=E\left[-\left.\frac{\partial^{2} l}{\partial \theta \partial \pi_{j}}\right|_{\theta=0}\right], \quad \text { for } j=1,2, \ldots, n .
$$

Under $H_{0}$, the maximum likelihood estimator of $\pi_{j}(j=1,2, \ldots, n)$, which is $\sqrt{n}$ - consistent, is $\hat{P}_{j}=\sum_{i=1}^{m} X_{i j} / \sum_{i=1}^{m} n_{i}=X_{0 j} / n$. Thus, the $C(\theta)$ test for goodness of fit of the multinomial distribution against the Dirichlet-multinomial alternatives refers the statistic

$$
Z=\frac{N \sum_{j=1}^{n}\left(1 / X_{0 j}\right) \sum_{i=1}^{K} X_{i j}\left(X_{i j}-1\right)-\sum_{i=1}^{K} n_{i}\left(n_{i}-1\right)}{\sqrt{2(n-1) \sum_{i=1}^{K} n_{i}\left(n_{i}-1\right)}}
$$

to a standard normal distribution. And else, Paul et al. (1989) mention that Smith $(1951$; 1952) proposes the same statistic for testing heterogeneity of multinomial proportions after apply some minor statistics.

Potthoff and Whittinghill (1966) ask if $n$ samples all came from multinomial distribution with the same probability parameters ( $p$ 's). Their paper approach the homogeneity testing by attempting to construct tests having maximal power against certain razonable alternative hypotheses when $p$ is known or specified or when $p$ is unkown. The spreading out could be the result of lack of independence (and, more specifically, positive correlation) among the $n_{i}$ elements of an individual simple; it could also result from different values of $p$ in the different samples.

For known $p$, let the $i$ th of $n$ samples be of size $s_{i}$, and let there be $X_{i 1}, X_{i 2}, \ldots, X_{i n}$ individuals observed respectively in $m$ classes. The null hypothesis is that, for each $i,\left(X_{i 1}, X_{i 2}, \ldots, X_{i n}\right)$ follows the multinomial distribution with simple size $s_{i}$ and with respective probabilities $p_{1}, p_{2}, \ldots, p_{n}$ for the $n$ classes. Potthoff and Whittinghill (1966) use for the alternative hyphotesis of non-homogeneity a model in which for each $i$, a random vector $\left(p_{1^{*}}, p_{2^{*}}, \ldots, p_{n^{*} i}\right)$ is drawn from a Dirichlet distribution with mean vector $\left(p_{1}, p_{2}, \ldots, p_{n}\right)$, and then $\left(X_{i 1}, X_{i 2}, \ldots, X_{i n}\right)$ is drawn from a multinomial distribution with parameters $\left(p_{1^{*} i}, p_{2^{*} i}, \ldots, p_{n^{*} i}\right)$. For specific $p_{j}$ 's, the locally most powerful test of the multinomial null hypothesis against the Dirichletmultinomial alternative has critical region based on large values of the statistic

$$
V=\sum_{j=1}^{m} X_{. j} / p_{j}
$$

where

$$
X_{\bullet j}=\sum_{i} X_{i j}\left(X_{i j}-1\right)=\sum_{i} X_{i j}^{2}-\sum_{i} X_{i j}
$$


The first two moments on the null hypothesis of $V$ are

$$
E(V)=N_{\bullet}, \quad \sigma^{2}(V)=2(m-1) N_{\bullet} .
$$

where

$$
N_{\bullet}=\sum_{i} n_{i}\left(n_{i}-1\right)=\sum_{i} n_{i}^{2}-\sum_{i} n_{i} .
$$

Thus, under the null hypothesis

$$
z=\left(V-N_{\bullet}\right) /\left[2(n-1) N_{\bullet}\right]^{1 / 2} .
$$

is approximately $N(0,1)$ for a sufficiently large experiment.

When the $p_{j}$ 's are unkwon they consider $V$ as a function of $p$, then the values of $p$ which minimize $V$ of the equation (27) are

$$
p_{j}=X_{\bullet j}^{1 / 2} / \sum_{j=1}^{n} X_{\bullet j}^{1 / 2}
$$

for which

$$
V=V_{\min }=\left(\sum_{j=1}^{n} X_{\bullet j}^{1 / 2}\right)^{2} .
$$

Thus $V$ of the equation (17) can be no smaller than (23) no matter what the values of the unkown $p_{j}$ 's.

Potthoff and Whittinhill (1966) define a new test based on the $V$ of the equation (17), so they choose a linear function of $V$ whose first three moments on the null hypothesis are equal to those of a chi-square distribution, so they take

$$
e V+f \text { follows a } \chi_{v}^{2}
$$

where

$$
e=\frac{N .}{2(n-1)\left(\sum_{j=1}^{n} \frac{1}{p_{j}}-3 n+2\right) N+\sum_{i} n_{i}\left(n_{i}-1\right)\left(n_{i}-2\right)},
$$

and

$$
v=e^{2}(n-1) N .
$$


where the constants $e, f$, and $v$ are determined so that the left and right sides of (24) have the same first three moments, and $v$ is the degrees of freedom of a central chisquare.

\subsection{Prior Dirichlet and posterior Dirichlet}

The Dirichlet prior is conjugate to the multinomial likelihood, producing a Dirichlet posterior. The multinomial distribution is a generalization of the binomial for more than two categories, its probability function is

$$
p(\bar{x} \mid m, \bar{\theta})=\left(\begin{array}{c}
m \\
x_{1}, x_{2}, \ldots, x_{n}
\end{array}\right) \theta_{1}^{x_{1}} \theta_{2}^{x_{2}} \cdots \theta_{n}^{x_{n}}
$$

Therefore $p(\bar{x} \mid m, \bar{\theta}) \propto \prod_{j=1}^{n} \theta_{j}^{x_{j}}$.

The Dirichlet is a multivariate generalization of the beta

$$
p(\bar{\theta} \mid \bar{l})=\frac{\Gamma\left(l_{1}+l_{2}+\cdots+l_{n}\right)}{\Gamma\left(l_{1}\right) \Gamma\left(l_{2}\right) \cdots \Gamma\left(l_{n}\right)} \theta_{1}^{l_{1}-1} \theta_{2}^{l_{2}-1} \cdots \theta_{n}^{l_{n}-1}
$$

Therefore the Dirichlet prior is $p(\bar{\theta} \mid \bar{l})=\propto \prod_{j} \theta_{j}^{l_{j}-1}$. This one is conjugate to the multinomial likelihood, producing a Dirichlet posterior:

$$
\begin{aligned}
p(\bar{\theta} \mid \bar{l}) \times p(\bar{x} \mid m, \bar{\theta}) & \propto \prod_{j} \theta_{j}^{l_{j}-1} \prod_{j} \theta_{j}^{x_{j}} \\
& \propto \prod_{j} \theta_{j}^{l_{j}-1+x_{j}}
\end{aligned}
$$

These statistical devices can help us to distinguish and find significant changes at the economic data series by clusters of economies.

\section{IS IT A MULTINOMIAL DISTRIBUTION OR A DIRICHLET- MULTINOMIAL DISTRIBUTION?}

\subsection{Overdispersion: estimation of the Dirichlet and Dirichlet-multinomial distributions}

Hernández-Veleros (2008) tests to see if the proportions of significant positive annual growth rates $\left(\theta_{1 i}^{j}\right)$-augmentation regimen- are equal for any $j(=1,2, \ldots, 5)$ decade for the cluster $i(=1,2, \ldots, 7)$ with relation to the proportion of significant positive annual growth rates for the complete period 1951-2000 for that cluster $i$ $\left(\theta_{1, i}\right)$, using a chi-square test. He can not deny the null hypotheses $\left(H_{0}\right.$ : proportions are equal) for clusters 1,2,6 and 7, but he refuses to accept the null hypotheses for clusters 3,4 , and 5 (table 2 ). 
For the proportions of significant negative annual growth rates (diminution regimen), he can not deny the null hypotheses for any clusters, and with the tests for the proportions of no significant annual growth rates (stagnation regimen), he comes to the same conclusion: no denial that the proportions are equal for all seven clusters (table 2).

TABLE 2

Test to analyze if the proportions of growth rates by regimen are equal for all the decades from 1951-2000.

\begin{tabular}{|cccc|}
\hline \multirow{2}{*}{ Cluster } & \multicolumn{3}{c|}{$\boldsymbol{H}_{0}$ : proportions are equal for } \\
\cline { 2 - 4 } & $\begin{array}{c}\text { Significant } \\
\text { positive regimen }\end{array}$ & $\begin{array}{c}\text { Significant } \\
\text { negative regimen }\end{array}$ & $\begin{array}{c}\text { No significant } \\
\text { regimen }\end{array}$ \\
\hline 1 & No refuse $H_{0}$ & No refuse $H_{0}$ & No refuse $H_{0}$ \\
2 & No refuse $H_{0}$ & No refuse $H_{0}$ & No refuse $H_{0}$ \\
3 & Refuse $H_{0}$ & No refuse $H_{0}$ & No refuse $H_{0}$ \\
4 & Refuse $H_{0}$ & No refuse $H_{0}$ & No refuse $H_{0}$ \\
5 & Refuse $H_{0}$ & No refuse $H_{0}$ & No refuse $H_{0}$ \\
6 & No refuse $H_{0}$ & No refuse $H_{0}$ & No refuse $H_{0}$ \\
7 & No refuse $H_{0}$ & No refuse $H_{0}$ & No refuse $H_{0}$ \\
\hline
\end{tabular}

From: Hernández-Veleros (2008).

We compare, as Mosimann (1962) does in his forest fossil pollen count analysis, the observed variances of the counts of each of the three economic performance regimens (augmentation, stagnation and diminution) with the fitted variances considering constant proportions from decade to decade using the formula $S_{i}^{2}=\bar{x}_{i}\left(m-\bar{x}_{i}\right) m$, where $m$ is the number of growth rates by decade for that cluster and $\bar{x}_{i}$ is the average of growth rates in that economic performance regimen by decade. We see that the first variances are greater than the latter, except during the diminution regimen for clusters 2,3 and 7 , and at the augmentation regimen for cluster 7 . Thus, 17 of 21 calculated $F$-tests as ratios of the observed variances with respect to their multinomial variances are significant at 5 percent $\left(F_{(5, \infty)}=2.2\right)$. Therefore, the proportions change from decade to decade (table 3$)$.

TABLE 3

Test to analyze changes in the proportions of the economic performance regimens by cluster, 1951-2000.

\begin{tabular}{|cccccccccc|}
\hline \multirow{2}{*}{ Cluster } & \multicolumn{3}{c}{$\begin{array}{c}\text { Variances of the } \\
\text { counts by regimen }\end{array}$} & \multicolumn{3}{c}{$\begin{array}{c}\text { Variances with constant } \boldsymbol{p} \text { 's by } \\
\text { regimen }\end{array}$} & \multicolumn{3}{c|}{ F statistics } \\
\cline { 2 - 10 } & Augment. & Stagnat. & Diminut. & Augment. & Stagnat. & Diminut. & Augment. & Stagnat. & Diminut. \\
\hline 1 & 226.7 & 348.5 & 140.7 & 27.9 & 59.9 & 54.5 & 8.1 & 5.8 & 2.6 \\
2 & 305.5 & 404.0 & 37.0 & 41.7 & 68.7 & 52.5 & 7.3 & 5.9 & 0.7 \\
3 & 579.3 & 746.8 & 26.5 & 45.0 & 53.4 & 20.7 & 12.9 & 14.0 & 1.3 \\
4 & 217.8 & 767.2 & 241.3 & 18.2 & 47.1 & 43.2 & 12.0 & 16.3 & 5.6 \\
5 & 216.7 & 729.8 & 209.8 & 22.6 & 46.1 & 34.0 & 9.6 & 15.8 & 6.2 \\
6 & 26.8 & 286.0 & 138.3 & 6.2 & 34.9 & 31.9 & 4.4 & 8.2 & 4.3 \\
7 & 19.7 & 49.7 & 14.5 & 12.2 & 18.3 & 9.0 & 1.6 & 2.7 & 1.6 \\
\hline
\end{tabular}


Thus, there is evidence of structural changes in probabilities or frequencies by regimen if we use the $F$-tests for all clusters, except cluster 7 .

However, how many structural changes by economic performance regimens (significant changes in frequencies or probabilities) do we find by cluster and when did they happen? In order to answer these questions we calculate the ratios of the variances of the counts for each decade among the consecutive results of the three regimens (augmentation, stagnation and diminution). We find 41 structural changes significant for 5 percent $\left(F_{(2, \infty)}=3.0\right)$ between consecutive decades for all clusters (table 4); for example, cluster 4 has eight structural changes: three in the augmentation regimen, three in the stagnation regimen and two in the diminution regimen. Therefore, we can define four sub-periods for the augmentation regimen (1951-1960, 1961-1970, 1971-1980 and 1981-2000), four sub-periods for the stagnation regime (1951-1960, 1961-1980, 1981-1990 and 1991-2000) and three sub-periods for the diminution regimen (1951-1960, 1961-1980 and 1981-2000) (figure A1 in annex). However, we need to know if these structural changes are significant in order to use a Dirichlet-multinomial instead of a multinomial distribution.

TABLE 4

Structural changes in the proportions of the economic performance regimes by cluster and by decade, 1951-2000.

\begin{tabular}{|ccccc|}
\hline Cluster & Augmentation & Stagnation & Diminution & All regimens \\
\hline 1 & 2 & 2 & 2 & 6 \\
2 & 2 & 1 & 0 & 3 \\
3 & 3 & 3 & 0 & 6 \\
4 & 3 & 3 & 2 & 8 \\
5 & 2 & 3 & 3 & 8 \\
6 & 1 & 3 & 1 & 5 \\
7 & 1 & 2 & 2 & 5 \\
All clusters & 14 & 17 & 10 & 41 \\
\hline
\end{tabular}

With the purpose of estimating the parameters of the Dirichlet distribution (table 6) and its respective standard errors, we employ a Stata command used to estimate fixed-effect negative binomial models, as Guimarães (2005) suggests. We also estimate two overdispersion coefficients $\rho=\left(1+l_{1}+l_{2}+l_{3}\right)^{-1 / 2}$ and $\theta=\rho^{2}$, where $\theta$ is named by Guimarães (2005) as the intra-class correlation coefficient (table 5). If overdispersion doesn't occur, then the Dirichlet-multinomial distribution (table 7) collapses to multinomial distribution. The minimum overdispersion factor $((m+c) /(1+c))$ corresponds to cluster 7 ; the maximum to cluster 4 . 
TABLE 5

Parameters of Dirichlet distribution and overdispersion factor by cluster, 1951-2000.

\begin{tabular}{|ccccccccc|}
\hline \multirow{2}{*}{ Parameter* $^{*}$} & $\mathbf{1}$ & $\mathbf{2}$ & $\mathbf{3}$ & $\mathbf{4}$ & $\mathbf{5}$ & $\mathbf{6}$ & $\mathbf{7}$ \\
\cline { 2 - 8 } & 6.693 & 16.338 & 11.003 & 2.178 & 4.315 & 2.063 & 30.071 \\
$I_{1}$ & 26.775 & 51.823 & 26.480 & 11.359 & 23.241 & 38.440 & 160.294 \\
$I_{3}$ & 18.283 & 23.148 & 4.575 & 7.524 & 7.167 & 13.633 & 21.175 \\
$\sum_{i=1}^{3} I_{i}=c=\theta^{-1}$ & 51.750 & 91.309 & 42.059 & 21.061 & 34.723 & 54.136 & 211.540 \\
$\theta=\rho^{2}=\frac{1}{1+c}$ & 0.138 & 0.104 & 0.152 & 0.213 & 0.167 & 0.135 & 0.069 \\
$\frac{m+c}{1+c}=1+\rho^{2}(m-1)$ & 1.076 & 1.043 & 1.093 & 1.181 & 1.112 & 1.073 & 1.019 \\
\hline
\end{tabular}

*: The subscripit 1 indicates the augmentation regimen, the subscript 2 indicates the diminution regimen and the subscripit 3 the stagnation regimen.

TABLE 6

Statistical indicators of the Dirichlet distribution for cluster, 1951-2000.

\begin{tabular}{|lccccccc|}
\hline \multicolumn{7}{c}{$\begin{array}{c}\text { Statistical } \\
\text { Indicator }\end{array}$} & \multicolumn{7}{c}{ Cluster } \\
\cline { 2 - 8 } & $\mathbf{1}$ & $\mathbf{2}$ & $\mathbf{3}$ & $\mathbf{4}$ & $\mathbf{5}$ & $\mathbf{6}$ & $\mathbf{7}$ \\
\hline $\mathrm{E}\left(p_{1}\right)$ & 0.51738 & 0.56756 & 0.62960 & 0.53935 & 0.66933 & 0.71006 & 0.75775 \\
$\mathrm{E}\left(p_{2}\right)$ & 0.12933 & 0.17893 & 0.26162 & 0.10340 & 0.12426 & 0.03811 & 0.14215 \\
$\mathrm{E}\left(p_{3}\right)$ & 0.35329 & 0.25351 & 0.10878 & 0.35725 & 0.20642 & 0.25183 & 0.10010 \\
$\operatorname{Var}\left(p_{1}\right)$ & 0.00473 & 0.00266 & 0.00542 & 0.01126 & 0.00620 & 0.00373 & 0.00086 \\
$\operatorname{Var}\left(p_{2}\right)$ & 0.00213 & 0.00159 & 0.00449 & 0.00420 & 0.00305 & 0.00066 & 0.00057 \\
$\operatorname{Var}\left(p_{3}\right)$ & 0.00433 & 0.00205 & 0.00225 & 0.01041 & 0.00459 & 0.00342 & 0.00042 \\
$\operatorname{Cov}\left(p_{1}, p_{2}\right)$ & -0.00127 & -0.00110 & -0.00383 & -0.00253 & -0.00233 & -0.00049 & -0.00051 \\
$\operatorname{Cov}\left(p_{2}, p_{3}\right)$ & -0.00087 & -0.00049 & -0.00066 & -0.00167 & -0.00072 & -0.00017 & -0.00007 \\
$\operatorname{Cov}\left(p_{1}, p_{3}\right)$ & -0.00347 & -0.00156 & -0.00159 & -0.00873 & -0.00387 & -0.00324 & -0.00036 \\
$\operatorname{Mode}\left(p_{1}\right)$ & 0.52871 & 0.57552 & 0.65236 & 0.57357 & 0.70110 & 0.73217 & 0.76385 \\
$\operatorname{Mode}\left(p_{2}\right)$ & 0.11677 & 0.17368 & 0.25611 & 0.06521 & 0.10449 & 0.02079 & 0.13940 \\
$\operatorname{Mode}\left(p_{3}\right)$ & 0.35452 & 0.25080 & 0.09153 & 0.36122 & 0.19441 & 0.24704 & 0.09674 \\
$\theta_{12}$ & -0.39905 & -0.53480 & -0.77605 & -0.36746 & -0.53591 & -0.31150 & -0.71995 \\
$\theta_{13}$ & -0.76527 & -0.66762 & -0.45549 & -0.80670 & -0.72559 & -0.90791 & -0.58986 \\
$\theta_{23}$ & -0.28486 & -0.27204 & -0.20796 & -0.25318 & -0.19211 & -0.11548 & -0.13577 \\
\hline
\end{tabular}

*: The subscript 1 indicates the augmentation regimen, the subscript 2 indicates the diminution regimen and the subscript 3 the stagnation regimen.

The greatest volatility of the augmentation regimen, measured by $\operatorname{Var}\left(X_{1}\right)$, corresponds to cluster four and the lowest volatility to cluster seven: $v_{7}<v_{6}<v_{5} \leq$ $v_{3} \leq v_{2}<v_{1} \leq v_{4}$ (table 7).

The greatest volatility of the diminution regimen, $\operatorname{Var}\left(X_{2}\right)$, belongs to cluster three and the lowest volatility of this regimen is in cluster six: $v_{6}<v_{4}<v_{1} \leq v_{5} \leq v_{7}$ $<v_{2}<v_{3}$ (table 7).

For the variance of the stagnation regimen, $\operatorname{Var}\left(X_{3}\right)$, we have the next order: $v_{7}$ $<v_{3}<v_{5}<v_{2} \leq v_{6}<v_{1}<v_{4}($ table 7$)$. 
Because we are comparing different averages, the correct measurement for the dispersion analysis is the coefficient of variation, since the standard deviation is only significant for the specific average to which it calculates. In this case we have the following ascending order for the positive growth regimen: $c v_{7}<c v_{6}<c v_{5}<c v_{3}$ $<c v_{2}<c v_{1} \leq c v_{4}$ (table 7).

For the diminution regimen, the ascending order of the coefficient of variation is the following: $c v_{3}<c v_{2}<c v_{7}<c v_{1}<c v_{5}<c v_{4}<c v_{6}$ (table 7).

Finally, the ascending order of the coefficient of variation of the stagnation regimen is as follows: $c v_{1} \leq c v_{4}<c v_{2}<c v_{6}<c v_{5}<c v_{3} \leq c v_{7}$ (table 7).

The Dirichlet-multinomial distribution gives us different results for the variance-covariance matrix among the three economic performance regimens if we compare with the results from the multinomial distribution (tables 7 and A1) ${ }^{3}$.

TABLE 7

Statistical indicators of the Dirichlet-multinomial distribution for cluster by economic performance regimen, 1951-2000.

\begin{tabular}{|lccccccc|}
\hline \multicolumn{1}{c}{$\begin{array}{c}\text { Statistical } \\
\text { indicator }\end{array}$} & $\mathbf{1}$ & $\mathbf{2}$ & $\mathbf{3}$ & $\mathbf{4}$ & $\mathbf{5}$ & $\mathbf{6}$ & $\mathbf{7}$ \\
\cline { 2 - 9 } & 2.59 & 2.84 & 3.15 & 2.70 & 3.35 & 3.55 & 3.79 \\
$\mathrm{E}\left(X_{1}\right)$ & 0.65 & 0.89 & 1.31 & 0.52 & 0.62 & 0.19 & 0.71 \\
$\mathrm{E}\left(X_{2}\right)$ & 1.77 & 1.27 & 0.54 & 1.79 & 1.03 & 1.26 & 0.50 \\
$\mathrm{E}\left(X_{3}\right)$ & 1.34 & 1.28 & 1.27 & 1.47 & 1.23 & 1.10 & 0.94 \\
$\operatorname{Var}\left(X_{1}\right)$ & 0.61 & 0.77 & 1.06 & 0.55 & 0.61 & 0.20 & 0.62 \\
$\operatorname{Var}\left(X_{2}\right)$ & 1.23 & 0.99 & 0.53 & 1.36 & 0.91 & 1.01 & 0.46 \\
$\operatorname{Var}\left(X_{3}\right)$ & -0.36 & -0.53 & -0.90 & -0.33 & -0.46 & -0.15 & -0.55 \\
$\operatorname{Cov}\left(X_{1}, X_{2}\right)$ & -0.98 & -0.75 & -0.37 & -1.14 & -0.77 & -0.96 & -0.39 \\
$\operatorname{Cov}\left(X_{1}, X_{3}\right)$ & -0.25 & -0.24 & -0.16 & -0.22 & -0.14 & -0.05 & -0.07 \\
$\operatorname{Cov}\left(X_{2}, X_{3}\right)$ & -0.40 & -0.53 & -0.78 & -0.37 & -0.54 & -0.31 & -0.72 \\
$\theta\left(X_{1}, X_{2}\right)$ & -0.28 & -0.27 & -0.21 & -0.25 & -0.19 & -0.12 & -0.14 \\
$\theta\left(X_{1}, X_{3}\right)$ & -0.77 & -0.67 & -0.46 & -0.81 & -0.73 & -0.91 & -0.59 \\
$\theta\left(X_{2}, X_{3}\right)$ & 1.076 & 1.043 & 1.093 & 1.181 & 1.112 & 1.073 & 1.019 \\
$(\mathrm{~m}+\mathrm{c}) /(1+\mathrm{c})$ & & & &
\end{tabular}

*: The subscript 1 indicates the augmentation regimen, the subscript 2 indicates the diminution regimen and the subscript 3 the stagnation regimen.

We employ the Dirichlet-multinomial distribution to estimate a growth trend for the decade 1991-2000. Clusters six and five have the best results, with $2.09 \%$ percent and $1.98 \%$ annual growth rates, respectively. The worst results are for cluster three with a growth rate of $0.48 \%$. The ascending order of these long term trends is: $c_{3}<c_{2}<c_{4}<c_{7}<c_{1}<c_{5}<c_{6}$ (table 8).

\footnotetext{
${ }^{3}$ We can compare the results of the table 7 with the results of Hernández-Veleros (2008) at the table A1 in the annex.
} 
We estimate the following volatility by the decade 1991-2000: cluster one has the greatest standard deviation: 3.60, and cluster seven the least one: 2.03 . The ascending order of the standard deviations of the growth rates from this decade is: $c_{7}<c_{2} \leq c_{4} \leq c_{3}<c_{6} \leq c_{5}<c_{1}$ (table 8).

Therefore, the ascending order of the coefficients of variation is: $c_{6} \leq c_{5}<c_{7}<$ $c_{1}<c_{4}<c_{2}<c_{3}$ (table 8).

If we compare these last results with the trends, variances and coefficients of variation from the multinomial distribution we find big changes; for example the coefficients of variation are greater for the clusters two, three, four, six and seven $(\text { table } \mathrm{A} 2)^{4}$.

TABLE 8

Statistical indicators for clusters using the Dirichlet-multinomial distribution, 1991-2000.

\begin{tabular}{|lccccccc|}
\hline \multirow{2}{*}{ Statistical indicador } & \multicolumn{7}{c|}{ Cluster } \\
\cline { 2 - 9 } & $\mathbf{1}$ & $\mathbf{2}$ & $\mathbf{3}$ & $\mathbf{4}$ & $\mathbf{5}$ & $\mathbf{6}$ & $\mathbf{7}$ \\
\hline Trend & 1.9125 & 0.5493 & 0.4858 & 1.0301 & 1.9839 & 2.0632 & 1.5813 \\
Variance & 3.6047 & 2.1156 & 2.2763 & 2.1198 & 2.6436 & 2.6273 & 2.0302 \\
Coefficient of variation & 0.9928 & 2.6480 & 3.1059 & 1.4134 & 0.8196 & 0.7856 & 0.9011 \\
\hline
\end{tabular}

We estimate the coefficients of variation for the five decades by cluster, then we averaging them in order to compare these estimations with the results of Hernández-Veleros (2008). After that, we calculate the absolute difference between the multinomial estimation and the Dirichlet-multinomial estimation and find the littlest difference at the cluster seven: the ascending order of these coefficients of variation is: $c_{7}<c_{6}<c_{1}<c_{2}<c_{5}<c_{3}<c_{4}$ (table 9). Therefore, probably we won't find differences between the multinomial and Dirichlet-multinomial distributions for the clusters seven and six.

TABLE 9

Coefficient of variation for clusters using the multinomial and the Dirichlet-multinomial distributions, 1951-2000.

\begin{tabular}{|cccc|}
\hline Cluster & Multinomial & $\begin{array}{c}\text { Dirichlet- } \\
\text { multinomial }\end{array}$ & $\begin{array}{c}\text { Absolute } \\
\text { difference }\end{array}$ \\
\hline 1 & 1.1152 & 0.9489 & 0.1663 \\
2 & 1.1256 & 1.3931 & 0.2674 \\
3 & 1.4705 & 2.5429 & 1.0724 \\
4 & 0.8594 & 2.2155 & 1.3561 \\
5 & 0.7985 & 1.1185 & 0.3201 \\
6 & 0.7007 & 0.7332 & 0.0325 \\
7 & 0.8276 & 0.8148 & 0.0128 \\
\hline
\end{tabular}

\footnotetext{
${ }^{4}$ We compare the results of table 8 with the results of Hernández-Veleros (2008) on table A2 in the annex.
} 


\subsection{Homogeneity tests}

In order to evaluate the first hypothesis: significant overdispersion at the multinomial distributions for seven clusters of economies and three regimens of economic performance - and with it to examine volatility and correlation between performance regimes- we must consider three tests: the $C(\theta)$ goodness-of-fit test statistics as Paul et al. (1989) suggest, the $z$ statistics and the $v$ statistics which Potthoff and Whittinghill (1966) suggest for $p_{i}$ 's unknown. For the $C(\theta)$ goodnessof-fit test statistics the null and alternative hypotheses are:

$H_{0}: \theta=0$ or multinomial distribution.

$H_{1}: \theta>0$ or Dirichlet-multinomial distribution.

Thus, only at cluster seven is it not possible to deny that the proportions did not change; therefore we cannot reject the null hypothesis for this cluster (Table 10).

TABLE 10

$C(\alpha)$ statistic by cluster, 1951-2000.

\begin{tabular}{|cccc|}
\hline Cluster & $\boldsymbol{C}(\alpha)$ & $\boldsymbol{p}$-value & Conclusion \\
\hline 1 & 8.09 & 0.00 & Refuse $H_{0}$ \\
2 & 5.88 & 0.00 & Refuse $H_{0}$ \\
3 & 11.85 & 0.00 & Refuse $H_{0}$ \\
4 & 17.26 & 0.00 & Refuse $H_{0}$ \\
5 & 14.33 & 0.00 & Refuse $H_{0}$ \\
6 & 6.55 & 0.00 & Refuse $H_{0}$ \\
7 & 0.89 & 0.18 & No refuse $H_{0}$ \\
\hline
\end{tabular}

The $z$ statistics from Potthoff and Whittinghill (1966) for $p_{i}{ }^{\prime}$ s unknown contain the next hypotheses:

$H_{0}$ : homogeneity or multinomial distribution.

$H_{1}$ : heterogeneity or Dirichlet-multinomial distribution.

As in the previous test for cluster seven only, we cannot reject the null hypothesis (table 11). 
TABLE 11

z statistic by cluster, 1951-2000.

\begin{tabular}{|cccc|}
\hline Cluster & $\boldsymbol{z}$ statistics & $\boldsymbol{p}$-value & Conclusion \\
\hline 1 & 7.96 & 0.00 & Refuse $H_{0}$ \\
2 & 5.82 & 0.00 & Refuse $H_{0}$ \\
3 & 11.75 & 0.00 & Refuse $H_{0}$ \\
4 & 16.79 & 0.00 & Refuse $H_{0}$ \\
5 & 14.11 & 0.00 & Refuse $H_{0}$ \\
6 & 6.36 & 0.00 & Refuse $H_{0}$ \\
7 & 0.89 & 0.18 & No refuse $H_{0}$ \\
\hline
\end{tabular}

The hypotheses Potthoff's $v$ statistics and Whittinghill (1966) are the same as in the $z$ statistics. The conclusion is also the same: not to reject the null hypothesis for cluster seven (table 12).

$H_{0}$ : homogeneity or multinomial distribution.

$H_{1}$ : heterogeneity or Dirichlet-multinomial distribution.

TABLE 12

$v$ statistics by cluster, 1951-2000.

\begin{tabular}{|cccccc|}
\hline Cluster & $\boldsymbol{V}$ & $\mathbf{g}$ de I & $\chi^{2}: \mathbf{e V + f}$ & $\boldsymbol{p}$-value & Conclusion \\
\hline 1 & 10.0229311 & 10 & 45.6535567 & 0.00 & Refuse $H_{0}$ \\
2 & 10.0331222 & 10 & 36.0848553 & 0.00 & Refuse $H_{0}$ \\
3 & 9.94678623 & 10 & 62.3536549 & 0.00 & Refuse $H_{0}$ \\
4 & 9.99907392 & 10 & 85.0963855 & 0.00 & Refuse $H_{0}$ \\
5 & 9.97685731 & 10 & 72.9834616 & 0.00 & Refuse $H_{0}$ \\
6 & 9.56018366 & 10 & 37.3617739 & 0.00 & Refuse $H_{0}$ \\
7 & 9.74151791 & 10 & 13.6742081 & 0.19 & No refuse $H_{0}$ \\
\hline
\end{tabular}

Therefore, we find significant overdispersion for all clusters, except for cluster seven. We must use the Dirichlet-multinomial distribution in order to get the variance-covariance matrix, so we have heterogeneous growth cycles for six clusters.

\subsection{Frequentist-Bayes debate}

Under the Frequentist view we estimate each parameter $p_{i j}$ - probability of or frequency of regimen $i$ at cluster $j$, with $p_{1 j}+p_{2 j}+p_{3 j}=1$; where $j=1,2, \ldots, 7-$ taking the ML estimate — maximum likelihood estimate-: the value for $p_{i j}$ that maximizes the probability of the data. In the Bayesian view, $p_{i j}$ has the degree of 
belief we assign to it. If we assume a Dirichlet distribution as our posterior distribution over values of $p_{i j}$, in our case a Dirichlet prior - that is conjugate to the multinomial likelihood - we would update our prior belief based on data to obtain the posterior belief, which simply requires a Dirichlet posterior.

We define the Dirichlet prior distributions for our three growth regimens and ask: What is the probability that the augmentation regimen reaches or supercedes the registered probability by the decade from 1951-1960 — a decade with high proportions of significant positive growth rates - (table 12)? The answer for clusters one, two, three and six is zero; for clusters four, five and seven is 0.74 , 0.03 and 0.67 , respectively.

TABLE 13

Accumulated frequency of growth rates by regimen, 1951-2000 and 1951-1960.

\begin{tabular}{|ccccc|}
\hline \multirow{2}{*}{ Cluster } & \multicolumn{3}{c}{ Regimens, 1951-2000 } & $\begin{array}{c}\text { Augmentation regimen, } \\
1951-1960\end{array}$ \\
\cline { 2 - 4 } & Diminution & Augmentation & Stagnation & 0.60 \\
\hline 1 & 0.13 & 0.52 & 0.35 & 0.68 \\
3 & 0.18 & 0.57 & 0.25 & 0.77 \\
4 & 0.27 & 0.63 & 0.10 & 0.53 \\
5 & 0.11 & 0.54 & 0.35 & 0.70 \\
6 & 0.12 & 0.67 & 0.20 & 0.77 \\
7 & 0.04 & 0.71 & 0.25 & 0.75 \\
\hline
\end{tabular}

\section{CONCLUSIONS}

The Dirichlet-multinomial distribution is an alternative window to look at the low dependence among growth rates across decades and it help us to define an heterogeneous growth cycle for a group of economies.

When we find that a parameter - average, variance and/or trend- of a series changes over time we must research to see if these structural changes are statistically significant. In the same way, we can define when and how many structural changes happened in the vector of probabilities of economic performance regimens. Then we evaluate whether these changes imply using a Dirichletmultinomial distribution or a multinomial distribution. The first distribution is correct for clusters one to six, but the multinomial distribution is what is correct for cluster seven. Thus, we have heterogeneous growth cycles for the former clusters and a homogeneous cycle for the latter. By relaxing the condition of perseverance in proportions, frequencies, or probabilities in each economic performance regime by decade we obtain more correct estimates for their variances and covariances (Table 7). 
On the other hand, the long term growth trends, the volatilities and the coefficient of variations for the seven clusters, which Hernández-Veleros (2008) defines, change with the Dirichlet-multinomial distribution, because we define and use different geometric growth rates and frequencies by decade (Tables 8 and 9).

The homogeneous growth cycles employ analytical time not historic time. There is no difference when looking at an economy that during the first two decades is stagnant, then grows in the next two, and in the fifth decreases, or another economy that decreases in the first decade, stagnates in the next two, and grows during the last two decades. This means that the order in which the economic performances occur, do not make a difference. Thus, it is a static stochastic model. On the other hand, the heterogeneous growth cycle employs historic time and is a dynamic stochastic model.

For Romer (2002) the ultimate objective of research on economic growth is to determine whether there are possibilities for raising overall growth or bringing standards of living in poor countries closer to those in the world leaders. In this research we find reduced probabilities to see similar growth rates like those rates registered during the sixth decade of the last century, apart from clusters 4 and 7.

The challenge is explain why do we have these frequencies or probabilities by economic performance regimen and why do they change; the multinomial logit models can be used here.

\section{REFERENCES}

AGUIAR, Mark and GOPINATH, Gita (2007): "Emerging Market Business Cycles: The Cycle is the Trend." Journal of Political Economy, Vol. 115, pages 69-102.

ARIAS, Andres; HANSEN, Gary D. and OHANIAN, Lee E. (2006): "Why Have Business Cycle Fluctuations Become Less Volatile? National Bureau of Economic Research, Working Paper, 12079, 23 pages.

CECCHETTI, Stephen G.; FLORES-LAGUNES, Alfonso and KRAUSE, Stefan (2006): "Assessing the Sources of Changes in the Volatility of Real Growth". National Bureau of Economic Research, Working Paper, 11946, 32 pages.

CARRION-I-SILVESTRE, Josep Lluís; BARRIO-CASTRO, Tomas del and LÓPEZ-BAZO, Enrique (2005): "Breaking the Panels: An Application to the GDP per capita". Econometrics Journal, Vol. 8, pages 159-175.

DELONG, J.B. and SUMMERS, Lawrence H. (1984): "Is increased price flexibility stabilizing?" Working Paper No. 1686, National Bureau of Economic Research, 32 pages.

DELONG, J.B. and SUMMERS, Lawrence H. (1986): "Are business cycles symmetrical?" The American Business Cycle, Chicago, Chicago University Press, pages 166-179.

GORDON, Robert J. (2005): "What Caused the Decline in U.S. Business Cycle Volatility? National Bureau of Economic Research, Working Paper, 11777, 80 pages.

GUIMARÃES, Paulo (2005): "A Simple Approach to Fit the Beta-binomial Model". The Stata Journal, Vol. 5, 3, pages 385-394.

GUPTA, Rameshwar and RICHARDS, Donald St. P. (2001): "The History of the Dirichlet and Liouville Distributions". International Statistical Review, Vol. 69, 3, pages 433-446.

HANSEN, Bruce E. (2001): "The New Econometrics of Structural Change: Dating Breaks in U. S. Labor Productivity." Journal of Economic Perspectives, Vol. 15, No. 4, pages 117-128. 
HERNÁNDEZ-VELEROS, Zeus Salvador (2009): Crecimiento Económico y Fluctuaciones Cíclicas: La Importancia de la Estabilidad Macroeconómica. Doctoral dissertation, Universidad de Barcelona, 242 pages.

HERNÁNDEZ-VELEROS, Zeus Salvador (2008): "Equiprobable Growth Model and Growth Cycles: An Approximation to Persistence and Volatility", Ciencia Ergo Sum, Vol. 15, 1, pages 21-34.

HUANG, C.; LEE, L. and SHIN, Y. (1997): "On Stationarity Test in the Presence of Structural Breaks." Economic Letters, Vol. 55, pages 165-172.

HUANG, Ho-Chuan (2005): "Diverging evidence of convergence hypothesis." Journal of Macroeconomics, Vol. 27, pages 233-255.

JUSTINIANO, Alejandro and PRIMICERI, Giorgio E. (2006): "The Time-Varying Volatility of Macroeconomic Fluctuations." National Bureau of Economic Research, Working Paper, 12022, 50 pages.

KIM, Byung Soo and MARGOLIN, Barry H. (1992): "Testing Goodness of Fit of a Multinomial Model Against Overdispersed Alternatives." Biometrics, Vol. 48, No. 3, pages 711-719.

LARRAIN, Felipe and CHOY H., Se Kyu (2003): "Recesiones, apertura y régimen cambiario." Cuadernos de Economía, Year 40, No. 121, pages 668-677.

LAU, Sau-Him Paul (1997): "Using Stochastic Growth Models to Understand Unit Roots and Breaking Trends", Journal of Economic Dynamics and Control, Vol 21, pages 16451667.

MADDISON, Angus (2003): The World Economy: Historical Statistics, Paris: Organisation for Economic Co-operation and Development.

MCKAY, Alisdair and REIS, Ricardo (2006): "The Brevity and Violence of Contractions and Expansions". National Bureau of Economic Research, Working Paper, 12400, 73 pages.

MEJÍA REYES, Pablo (1999): "Classical Businesss Cycles in Latin America: Turning Points, Asymetries and International Synchronisation”. Estudios Económicos, Vol. 14, 2, pages 265-297.

MEJÍA REYES, Pablo (2003): No-linealidades y Ciclos Económicos, México: El Colegio Mexiquense, A. C. and Universidad Autónoma del Estado de México, 237 pages.

MOSIMANN, James E. (1962): "On the Compound Multinomial Distribution, the Multivariate beta-distribution, and Correlations among Proportions". Biometrika, Vol.49, 1-2, pages 65-82.

NEERCHAL, Nagaraj K. and MOREL, Jorge G. (2005): "An Improved Method for the Computation of Maximum Likelihood Estimates for Multinomial Overdispersion Models". Computational Statistics \& Data Analysis, Vol. 49, pages 33-43.

PAUL, Sudhir R.; LIANG, K.Y. and SELF, S.G. (1989): "On Testing Departure from the Binomial and Multinomial Assumptions". Biometrics, Vol. 45, pages 231-236.

PAUL, Sudhir R.; BALASOORIYA, Uditha and BANERJEE, Tathagata (2005): "Fisher Information Matrix of the Dirichlet-multinomial Distribution”. Biometrical Journal, Vol. 47, 2, pages 230-236.

PERRON, Pierre (1989): "The great crash, the oil price shock and the unit root hypothesis." Econometrica, Vol. 57, pages 1361-1401.

PERRON, Pierre and ZHU, Xiaokang (2005): "Structural Breaks with Deterministic and Stochastic Trends", Journal of Econometrics, Vol. 129, pages 65-119.

POTTHOFF, Richard F. and WHITTINGHILL, Maurice (1966): "Testing for homogeneity I. The Binomial and Multinomial Distributions". Biometrika, Vol. 53, 1-2, pages 167-182.

ORGANIZACIÓN PARA LA COOPERACIÓN Y EL DESARROLLO ECONÓMICOS (2002): Economic Outlook, No. 71 
RAFIQ, M.S. (2006): "Business Cycle Moderation - Good Policies or Good Luck: Evidence \& Explanations for the Euro Area." Discussion Paper Series 2006_21, Loughborough University, 42 pages.

ROMER, Christina (1992): "Remeasuring Business Cycles." National Bureau of Economic Research, Working Paper, 4150, 52 pages.

ROMER, Christina (1999): "Changes in Business Cycles: Evidence and Explanations". Journal of Economic Perspectives, Vol. 3, 2, pages 23-44.

SMITH, C.A.B. (1951): "A test for heterogeneity of proportions." Annals of Eugenics, Vol. 16, pages $16-25$.

SMITH, C.A.B. (1951): "A simplified heterogeneity test." Annals of Eugenics, Vol. 17, pages 35-36.

ROMER, David (2002): Macroeconomía Avanzada, Madrid: Ed. McGraw Hill, 629 pages.

WATSON, Mark W. (1992): "Business Cycle Durations and Potswar Stabilization of the U. S. Economy." American Economic Review, Vol. 84, pages 24-46.

ZARNOWITZ, Victor (1991): "What is a Business Cycle?" National Bureau of Economic Research, Working Paper, 3863, 86 pages 


\section{ANNEX}

FIGURE A1

Number of breaks and subperiods for economic performance regimen, 1951-2000.

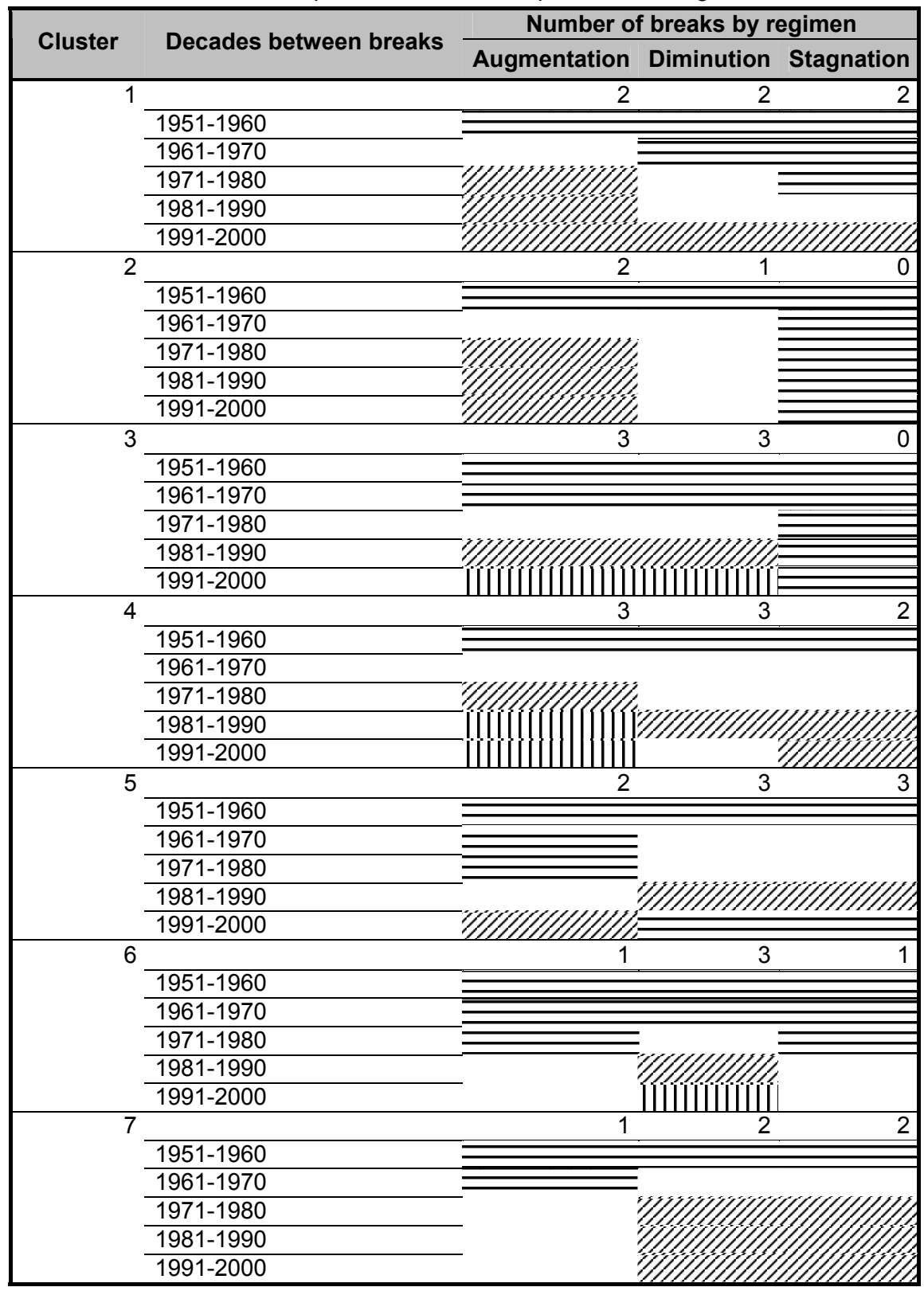


TABLE A1

Statistical indicators of the multinomial distribution for cluster by economic performance regimen, 1951-2000.

\begin{tabular}{|lccccccc|}
\hline \multicolumn{1}{c}{$\begin{array}{c}\text { Statistical } \\
\text { indicator }\end{array}$} & $\mathbf{1}$ & $\mathbf{2}$ & $\mathbf{3}$ & $\mathbf{4}$ & $\mathbf{5}$ & $\mathbf{6}$ & $\mathbf{7}$ \\
\cline { 2 - 8 } & 2.58 & 2.84 & 3.17 & 2.72 & 3.37 & 3.56 & 3.79 \\
$\mathrm{E}\left(X_{1}\right)$ & 0.67 & 0.91 & 1.33 & 0.54 & 0.61 & 0.19 & 0.71 \\
$\mathrm{E}\left(X_{2}\right)$ & 1.75 & 1.25 & 0.50 & 1.75 & 1.01 & 1.25 & 0.50 \\
$\mathrm{E}\left(X_{3}\right)$ & 1.25 & 1.23 & 1.16 & 1.24 & 1.10 & 1.03 & 0.92 \\
$\operatorname{Var}\left(X_{1}\right)$ & 0.58 & 0.74 & 0.98 & 0.48 & 0.54 & 0.18 & 0.61 \\
$\operatorname{Var}\left(X_{2}\right)$ & 1.14 & 0.94 & 0.45 & 1.14 & 0.81 & 0.94 & 0.45 \\
$\operatorname{Var}\left(X_{3}\right)$ & -0.35 & -0.52 & -0.84 & -0.29 & -0.41 & -0.13 & -0.54 \\
$\operatorname{Cov}\left(X_{1}, X_{2}\right)$ & -0.90 & -0.71 & -0.32 & -0.95 & -0.68 & -0.89 & -0.38 \\
$\operatorname{Cov}\left(X_{1}, X_{3}\right)$ & -0.23 & -0.23 & -0.13 & -0.19 & -0.12 & -0.05 & -0.07 \\
$\operatorname{Cov}\left(X_{2}, X_{3}\right)$ & -0.41 & -0.54 & -0.79 & -0.38 & -0.54 & -0.31 & -0.72 \\
$\theta\left(X_{1}, X_{2}\right)$ & -0.29 & -0.27 & -0.20 & -0.25 & -0.19 & -0.11 & -0.59 \\
$\theta\left(X_{1}, X_{3}\right)$ & -0.76 & -0.66 & -0.44 & -0.80 & -0.73 & -0.91 & -0.14 \\
$\theta\left(X_{2}, X_{3}\right)$ & & & & & & &
\end{tabular}

From: Hernández-Veleros (2008). Equiprobable Growth Model and Growth Cycles: An Approximation to Persistence and Volatility.

TABLE A2

Statistical indicators for clusters using the multinomial and the Dirichlet-multinomial distributions, 1951-2000 and 1991-2000.

\begin{tabular}{|c|c|c|c|c|c|c|c|c|}
\hline \multirow[b]{2}{*}{ Cluster } & \multicolumn{2}{|c|}{ Trend } & \multicolumn{2}{|c|}{ Variance } & \multicolumn{2}{|c|}{ Standard deviation } & \multicolumn{2}{|c|}{ Coef. of variation } \\
\hline & Multin.* & $\begin{array}{l}\text { Dirichlet- } \\
\text { mult.** }^{*}\end{array}$ & Multin.* & $\begin{array}{l}\text { Dirichlet- } \\
\text { mult.** }\end{array}$ & Multin.* & $\begin{array}{l}\text { Dirichlet- } \\
\text { mult. }^{* *}\end{array}$ & Multin.* & $\begin{array}{l}\text { Dirichlet- } \\
\text { mult. }^{* *}\end{array}$ \\
\hline 1 & 1.3526 & 1.9125 & 2.2754 & 3.6047 & 1.5084 & 1.8986 & 1.1152 & 0.9928 \\
\hline 2 & 1.3343 & 0.5493 & 2.2555 & 2.1156 & 1.5018 & 1.4545 & 1.1256 & 2.6480 \\
\hline 3 & 0.9339 & 0.4858 & 1.8858 & 2.2763 & 1.3733 & 1.5088 & 1.4705 & 3.1059 \\
\hline 4 & 1.8449 & 1.0301 & 2.5137 & 2.1198 & 1.5855 & 1.4560 & 0.8594 & 1.4134 \\
\hline 5 & 2.0137 & 1.9839 & 2.5852 & 2.6436 & 1.6079 & 1.6259 & 0.7985 & 0.8196 \\
\hline 6 & 2.3353 & 2.0632 & 2.6777 & 2.6273 & 1.6364 & 1.6209 & 0.7007 & 0.7856 \\
\hline 7 & 1.7167 & 1.5813 & 2.0186 & 2.0302 & 1.4208 & 1.4249 & 0.8276 & 0.9011 \\
\hline
\end{tabular}

*: Results for the periof $1951-2000$.

**: Results for the decade 1991-2000.

From: Hernández-Veleros (2008). Equiprobable Growth Model and Growth Cycles: An Approximation to Persistence and Volatility. 